\title{
New Title, New Editor, Broader Focus
}

Rapid change is so much a part of life today that it receives less attention, in and of itself, than it did a few years ago. Ways to manage change are devised or discovered, much as this journal and this column evolved. A solution was needed to handle the diffusion of increasing amounts of information relevant to the practicing health sciences librarian.

This issue marks several changes in this column: a new title, a new editor, and a broader focus. It is my intent to bring attention to issues of continuing education (or professional development) as they pertain to our role as educators. This is in addition to the column's original purpose of promoting an exchange of information about educating users of the library and other sources of information.

The broader focus is reflected in the column title: information management is not defined by any vehicle, such as a library. Information management is independent of these and so the column is free to report educational efforts which go beyond the walls of the library or information center. This is not a change in the column, but continues my predecessor's philosophy of information management education.

I will be working hard to avoid any change in the high level of quality the column has displayed since its beginning in 1982! The need for encouraging high standards of practice, supporting efficient methods of instruction and providing guidelines for programs is still very real, and this column will continue to address those needs.

Specifically, I would like to promote dialogue on the following topics in future issues:

- administrative aspects of educational programs: their delivery, staffing, cost benefit, and cost effectiveness; how this service fits into the institutional administrative structure; the desired credentials, experience and continuing education of instructors

- media of instruction: how computers, audiovisuals, print and others can be utilized most effectively for delivering and evaluating instruction

- research on how our educational activities advance knowledge of how people learn and how they find, use and store information

- descriptions of programs, particularly those which have stated needs assessment and evaluation components

- analysis of unsuccessful programs and descriptions of actions taken to change the outcome

- practical applications of educational theory, such as the use of a continuum of skills as a basis of instruction

I am always reminded, as I conclude a list, of that catchall, "Other duties as assigned." In this case too, there are many other areas related to information management education which will need to be examined and so, this is only a start; please add your suggestions by contacting me.

The format of the column will vary. Articles, editorial comment, notices of available materials, reports of meetings, reviews of instructional materials and other items will be considered for publication. I encourage phone calls or OnTyme messages (UNCHSL, addressed to me), copies of materials, publicity 
or manuscripts. Please include the name and phone number of the contact person on any materials sent.

Admittedly, I am influenced by events and trends in the academic health sciences environment but I am committed to encouraging and seeking out the perspectives from other settings. Remember the two watchwords: dialogue and exchange! I hope you will express your viewpoint through this column.

\section{Editorial Comment: What Is "Information Literacy"?}

Recent conversations with colleagues have prompted me to note their observations that some health sciences librarians are now, perceiving their role as educator to be "new." In large part, this notion seems to be a result of their efforts to teach users to conduct their own online searches. For some librarians, this may be their first and only formal instructional effort.

It seems to me that this picture, if it is accurate, parallels the impact that mediated online searching had on the library profession when it was first introduced. Suddenly, librarians felt that they had a new elevated status in the eyes of their users which, to some extent, was a reflection of the truth. Perhaps the truth was that we had failed previously to educate our users as to our professional roles and responsibilities.

Increasing self-awareness and renewed examination of our activities is a wonderful by-product of the impact of new information technology on our profession. Hopefully, it will launch more of us into instruction on a more basic level: how scientific information is generated and disseminated, including the traditional formats of this information which will be with us for some time. The following definition of information literacy is a more complete description of these basics:

“... 'information literacy,' an approximate definition of which would include the following elements:

- that solutions to many (not all) problems can be aided by the acquisition of appropriate facts and information;

- that knowledge of the variety of information resources available-who and where- is a requisite of this literacy;

- that the informing process, which is continual, is as important as the spot information process, which is occasional; and

- that there are strategies-when and how--of information acquisition." ${ }^{1}$

Information literacy, then, goes beyond the concept of computer literacy. The latter may be considered a component of the process of teaching some access strategies, but "Computer literacy has to do with increasing our understanding of what the machine can and cannot do. There are two major components of computer literacy: hardware and software."2

\footnotetext{
1 Taylor, R.S. "Reminiscing about the Future: Professional Education and the Information Environment." Library Journal 104(September 15, 1979):1875.

${ }^{2}$ Horton, F.W., Jr. "Information Literacy vs. Computer Literacy." ASIS Bulletin 9(April 1983):14.
} 
I make this distinction because, as one librarian so aptly stated, the emphasis on computer literacy serves to further exclude a major portion of our profession, particularly those in smaller or less affluent settings, from the arena of information management education. This occurs because of the equation of information management and computer applications. The fascination of new computer applications needs to be divorced from the basics of teaching information literacy, a role which has been served by librarians from day one.

Francesca Allegri

Head, Information Management Education

Health Sciences Library

University of North Carolina

Chapel Hill, NC

Please send your ideas, comments, materials or other items of interest to the Column Editor: Francesca Allegri, Head of Information Management Education, Health Sciences Library 223H, University of North Carolina at Chapel Hill, Chapel Hill, NC 27514. 